\title{
Screening of Diabetes and Hypertension Based on Retinal Fundus Photographs \\ Using Deep Learning
}

Guangzheng Dai ${ }^{1,2}$

Chenguang Zhang ${ }^{1,2}$

Wei $\mathrm{He}^{1-3}$

Corresponding Author: Wei He. Electonic address: hsyk2017@163.com

${ }^{1}$ Dalian Medical University, Dalian, Liaoning, China

${ }^{2}$ He Eye Specialists Hospitals, Shenyang, Liaoning, China

${ }^{3} \mathrm{He}$ University, Shenyang, Liaoning, China 


\section{Screening of Diabetes and Hypertension Based on Retinal Fundus Photographs}

\section{Using Deep Learning}

\section{ABSTRACT}

Purpose: The aim of this study was to use deep learning to screen for hypertension and diabetes based on retinal fundus images.

Methods: We collected 1160 retinal photographs which included 580 from patients with a diagnosis of hypertension or diabetes and 580 from normotensive and non-diabetic control. We divided this image dataset into (i) a development dataset to develop model and (ii) test dataset which were not present during the training process to assess model's performance. A binary classification model was trained by fine-tuning the classifier and the last convolution layer of deep residual network. Precision, recall, the area under the ROC (AUC), and the area under the Precision-Recall curve (AUPR) were used to evaluate the performance of the learned model.

Results: When we used 3-channel color retinal photographs to train and test model, its prediction precision for diabetes or hypertension was $65.3 \%$, the recall was $82.5 \%$, the AUC was 0.745 , and the AUPR was 0.742 . When we used grayscale retinal photographs to train and test model, its prediction precision was $70.0 \%$, the recall was $87.5 \%$, the AUC was 0.803 , and the AUPR was 0.779 .

Conclusions: Our study shows that trained deep learning model based on the retinal fundus photographs alone can be used to screen for diabetes and hypertension, although its current performance was not ideal. 


\section{INTRODUCTION}

Cardiovascular diseases are the world's biggest killers, and these diseases have remained the leading causes of death globally in the last 15 years. ${ }^{1}$ The key risk factors include hypertension, diabetes mellitus, dyslipidemia, cigarette smoking and obesity, which leads to progressive pathophysiological changes in various organs and tissues of the body, such as blood vessels of the brain, heart, kidney, eye. In particular, retinal vasculature, measuring 100 to $300 \mu \mathrm{m}$ in size, attracts a lot of non-ophthalmological attention, retinal microvascular abnormalities represent an ongoing systemic microvascular damage and can be viewed directly and noninvasively, offering a unique and easily accessible "window" to study the human microcirculation in vivo. Advances in digital retinal photography and computer image analysis have now enabled more objective quantitative assessment of retinal microvascular structure and function, and may offer a potential noninvasive research tool to assess the pathophysiology of microvasculature in cardiovascular diseases and generate a cardiovascular risk prediction tool.

Extensive research on retinal microvascular phenotypes in fundus images have shown that traditional cardiovascular risk factors, such as hypertension, ${ }^{2-22}$ diabetes mellitus, ${ }^{23-32}$ dyslipidemia, ${ }^{33-36}$ obesity, ${ }^{37-46}$ drinking, ${ }^{22,}, 33$ smoking, ${ }^{33}, 34,36,47$ can cause retinal microvascular abnormal signs to appear. These abnormal signs can be broadly divided into four groups: classic retinopathy(i.e., diabetic and hypertensive retinopathy), isolated retinopathy(e.g., retinal hemorrhage, microaneurysm, or cotton wool spot), changes in retinal vascular caliber(e.g., generalized retinal arteriolar narrowing, focal arteriolar 
narrowing, arteriovenous nicking), and changes in retinal vascular architecture (e.g., retinal tortuosity, fractal dimension, branching angle). These signs probably reflect systemic microvascular damage and may be an early indicator of cardiovascular diseases. There are some clinical studies supporting associations between retinal microvascular abnormalities and cerebral small-vessel disease (white matter lesions, lacunar infarcts, microbleeds), ${ }^{48-53}$ ischemic cerebral infarction, ${ }^{54-67}$ coronary atherosclerotic heart disease ${ }^{65,66,68-78}$ congestive heart failure. ${ }^{79-81}$ In addition, some prospective studies suggest that retinal microvascular abnormal signs are predictive of the subsequent risk of hypertension ${ }^{82-88}$ or diabetes ${ }^{89-93}$ independently of other known risk factors.

Although a large number of studies have reflected the association between abnormal retinal microvascular signs and cardiovascular risk factors, some results were inconsistent for two reasons. Firstly, qualitative assessment of retinopathy is mainly based on the experiences of the individual and the evaluation results lacks objectivity. Secondly, there is a variety of methods of computer-assisted quantification of retinal vasculature, such as retinal vessel caliber, and thus measurements given for the same fundus image often vary. Last but not least, variations in image brightness, focus, and contrast can significantly affect the measurement of retinal vasculature. Thus this study was designed to analyze retinal image using convolutional neural networks (CNN), also known as convnets, a type of deep-learning model almost universally used in computer vision applications. One fundamental characteristic of convnets that are composed of multiple processing layers is that it can find interesting features in the training data on its own, without any need for manual feature engineering. ${ }^{94}$ This is especially true for problems where the input samples are very 
high-dimensional, like medical images (e.g., retinal fundus image, optical coherence tomography, radiographs, tissue section). It can detect subclinical and discrete features appearing below the threshold of a human observer, quantify minimal differences in feature expression and recognize patterns among large cohorts. So we trained a CNN classification model to screen for hypertension and diabetes based on retinal fundus images.

\section{METHODS}

\section{Data collection}

The research followed the tenets of the Declaration of Helsinki and was reviewed by the Committee on Medical Ethics of Shenyang He Eye Hospital. We collected 427 patients with a diagnosis of hypertension or diabetes and 425 normotensive and non-diabetic control subjects, who were admitted between January 2018 and December 2018 to Shenyang He Eye Hospital with eye disease. The case group include 172 males and 255 females, mean age $64.1 \pm 9.6$ years, whereas the control group was composed of 201 males and 224 females, mean age $53.2 \pm 17.5$ years.

Each patient underwent ophthalmological examination and standard assessments of cardiovascular risk factors. Retinal photographs that were centred on the macula and documented the optic disc, the macula, substantial portions of the temporal vascular arcades were taken with $45^{\circ}$ non-mydriatic digital camera (TRC-NW300, Topcon, Tokyo, Japan) after dilation of the pupils with tropicamide phenylephrine eye drops. Hypertension was defined as systolic blood pressure greater than $140 \mathrm{~mm} \mathrm{Hg}$, diastolic blood pressure above $90 \mathrm{~mm} \mathrm{Hg}$, or use of antihypertensive medication during the previous 2 weeks. 
Diabetes mellitus was defined as a fasting blood glucose concentration above $7.0 \mathrm{mmol} / \mathrm{L}$, a non-fasting value of more than $11.1 \mathrm{mmol} / \mathrm{L}$, or a self-reported history of treatment for diabetes. Exclusion criteria were: poor dilation or ocular media opacities so that part of or the entire retinal vessel is almost indiscernible (ie, cataracts with high-severity opacity of lens, vitreous hemorrhage); any other previous or coexisting ocular disease that could affect the retinal vasculature (ie, glaucoma, central or branch retinal artery occlusion, central or branch retinal vein occlusion).

One thousand one hundred and sixty retinal photographs that include 580 from the case group and 580 from the control group. We divided this imaging datasets into a development dataset (1000 photos) to develop our models and test dataset (160 photos) which were not used during the training process to assess our model's performance. The development dataset consist of two components: 500 images from the patients with diabetes or hypertension and 500 images form the normotensive and non-diabetic control subjects. The development dataset was divided into a training dataset (70\%) and a validation dataset $(30 \%)$ which was a random subset of the development dataset and was not used to train the model parameters, but was used as a small evaluation dataset for tuning the model. The test dataset consist of two components: 80 images from the patients with diabetes or hypertension and 80 images form the normotensive and non-diabetic control subjects.

Model development

The JPEG content was decoded to RGB grids of pixels at a size of $2048 \times 1536$ and convert these into floating-point tensors. For pre-processing, auto-cutting was employed to minimize black border around the field of view and yields square images, of 
medRxiv preprint doi: https://doi.org/10.1101/2019.12.13.19013904; this version posted December 14, 2019. The copyright holder for this preprint (which was not certified by peer review) is the author/funder, who has granted medRxiv a license to display the preprint in perpetuity.

It is made available under a CC-BY-NC-ND 4.0 International license .

dimension $1496 \times 1496$, in order to scale the images without distortion. All images were resized to $256 \times 256$, and rescaled pixel values (between 0 and 255 ) to the $[0,1]$ interval. To highlight the retinal vasculature, two image enhancement methods, gamma correction and contrast limited adaptive histogram equalization, were conducted to enhance the image contrast (Fig. 1). In addition, another dataset was generated by converting all 3-channel color images to the grayscale ones (Fig. 1).

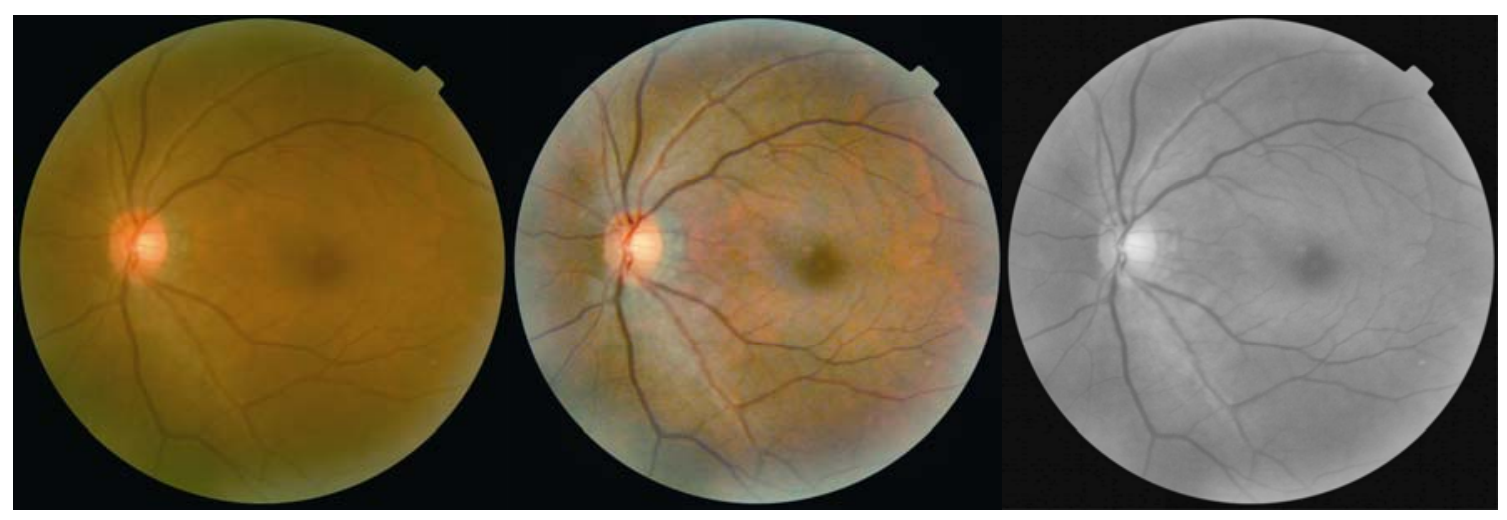

Figure 1. Right: original image; Middle: Enhanced image; Left: grayscale image

To avoid overfitting, data augmentation was adopted to generate more data from existing samples. The development dataset expands 1000 to 9000 through randomly extracting 9 patches of $224 \times 224$ from each $256 \times 256$ image, and each patch holds most of the vascular structure. During the training process, the training dataset via a number of random transformations, which include flipping half the images horizontally or vertically, rotating pictures within 45 degrees and translating pictures vertically or horizontally, yielding a number of believable-looking images, while the validation dataset were not augmented. 
Thus, at each iteration, the model never saw the exact same picture twice. This helps expose the model to more aspects of the data and generalize better.

Although data augmentation techniques were used, the inputs the model sees are still heavily inter-correlated, because they come from a small number of original images-you can't produce new information, you can only remix existing information. As such, this may not be enough to completely get rid of overfitting. To further combat overfitting, a common and highly effective approach to deep learning on small image datasets was to use a pretrained network that is a saved network which was previously trained on a large dataset, typically on a large-scale image-classification task. The features learned by the pretrained network can prove useful for many different computer-vision problems, even though these new problems may involve completely different classes than those of the original task. In this study, deep residual network, derived from the championship model on the ImageNet Large Scale Visual Recognition Challenge of 2015(ILSVRC 2015) classification task, which are substantially deeper than deep convolutional neural networks used previously and can gain accuracy from considerably increased depth, was used for training and classification ${ }^{95}$. Because this study is binary classification problem, we'll use a 2-way softmax classifier instead of the final layer with 1000 outputs and a softmax activation of the original model. We fine-tuned the classifier and the last convolution layer of resnet50, while all the other layers were be frozen, because layers higher up encode more-specialized features that need to be repurposed on new problem.

The mini-batch stochastic gradient descent (SGD) was used to optimize the trainable parameters of the resnet50. The learning rate was initialized at 0.0001 and successively 
decreased to $1 \times 10^{-8}$ of the original per iteration, and the maximum number of iterations was 500 . Momentum was used to addresses two issues with SGD : convergence speed and local minima.

Evaluating the model

In a test phase, in order to keep the image size consistent with cropped pictures during the training process, all testing images were resized to $225 \times 225$ and randomly extracted 1 patch of $224 \times 224$. To evaluate performances of the learned model on screening for diabetes and hypertension based on fundus, we used precision, recall, the area under the ROC (AUC) , the area under the Precision-Recall curve (AUPR) on separate test dataset which were not present in the development dataset.

\section{RESULTS}

First we used pre-processed 3-channel color retinal photographs to train and test model. Kept a record of how well the model did at each epoch and plotted the loss and accuracy of the model over the training and validation data during training (figure 2). The training accuracy increased gradually with every iteration until it reached nearly $90.3 \%$, while training loss kept decreasing until it reached nearly 0.241 . The training curves were closely tracking the validation curves. The model trained at 52th epoch performed best on the test dataset with accuracy of $69.4 \%$, and $75.7 \%$ on train dataset, $74.4 \%$ on validation dataset. On the test dataset, its prediction precision for diabetes or hypertension was $65.3 \%$, and the recall for diabetes or hypertension was $82.5 \%$. The model achieved an AUC of 0.745 , and an AUPR of 0.742. (Table 1) 


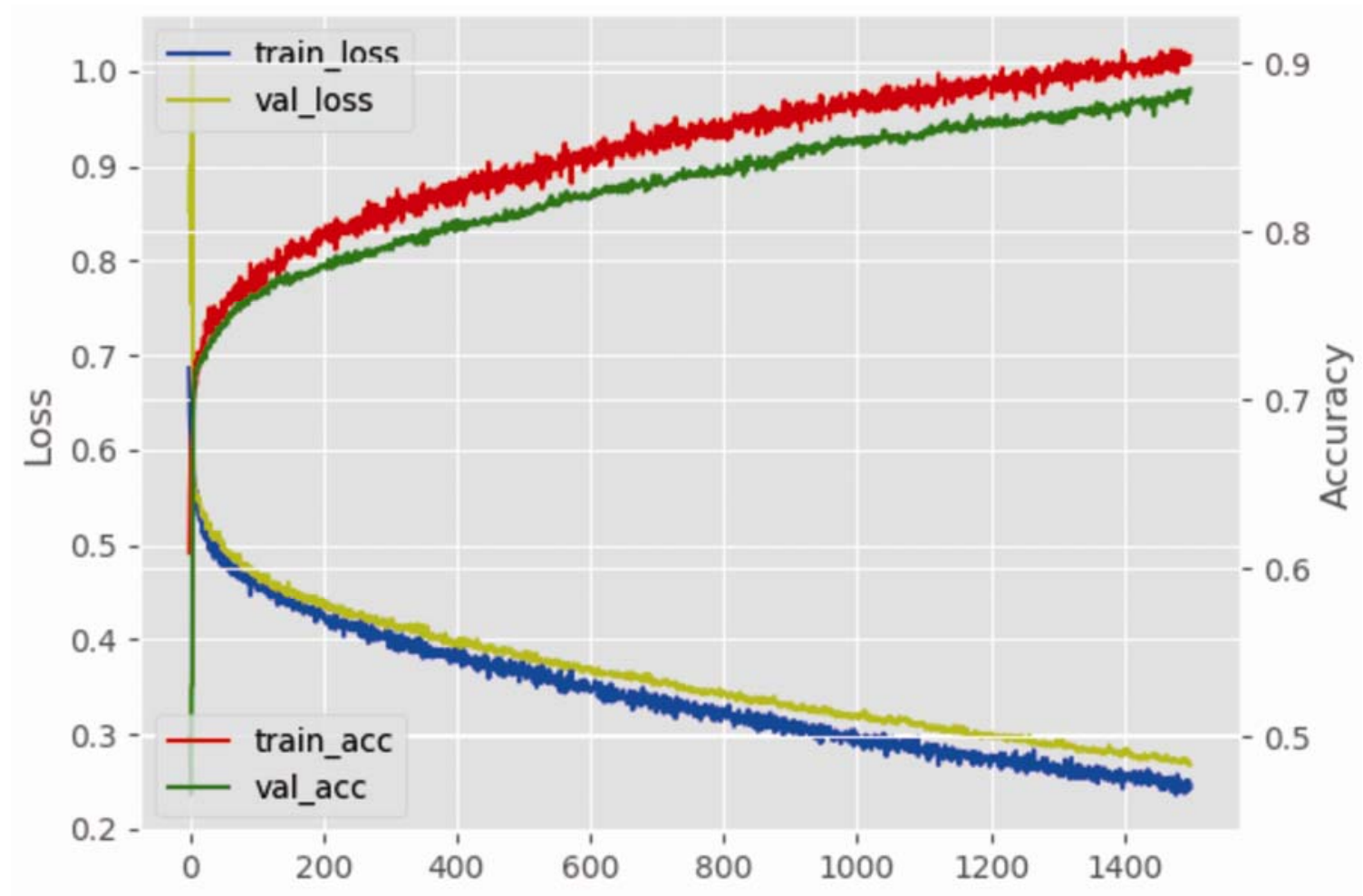

Figure 2. Training process on color retinal photographs

Next, we used pre-processed grayscale retinal photographs to train and test model. Kept a record of how well the model did at each epoch and plotted the loss and accuracy of the model over the training and validation data during training (figure 3). The training accuracy increased gradually with every iteration until it reached nearly $86.5 \%$, while validation loss kept decreasing until it reached nearly 0.317 . The training curves were closely tracking the validation curves. The model trained at 191 th epoch performed best on the test dataset with an accuracy of $75.0 \%$, and $77.9 \%$ on train dataset, $76.9 \%$ on validation dataset. On the test dataset its prediction precision for diabetes or hypertension was $70.0 \%$, and the recall for diabetes or hypertension was $87.5 \%$. The model achieved an AUC of 
medRxiv preprint doi: https://doi.org/10.1101/2019.12.13.19013904; this version posted December 14, 2019. The copyright holder for this preprint (which was not certified by peer review) is the author/funder, who has granted medRxiv a license to display the preprint in perpetuity.

It is made available under a CC-BY-NC-ND 4.0 International license .

0.803, and an AUPR of 0.779. (Table 1)

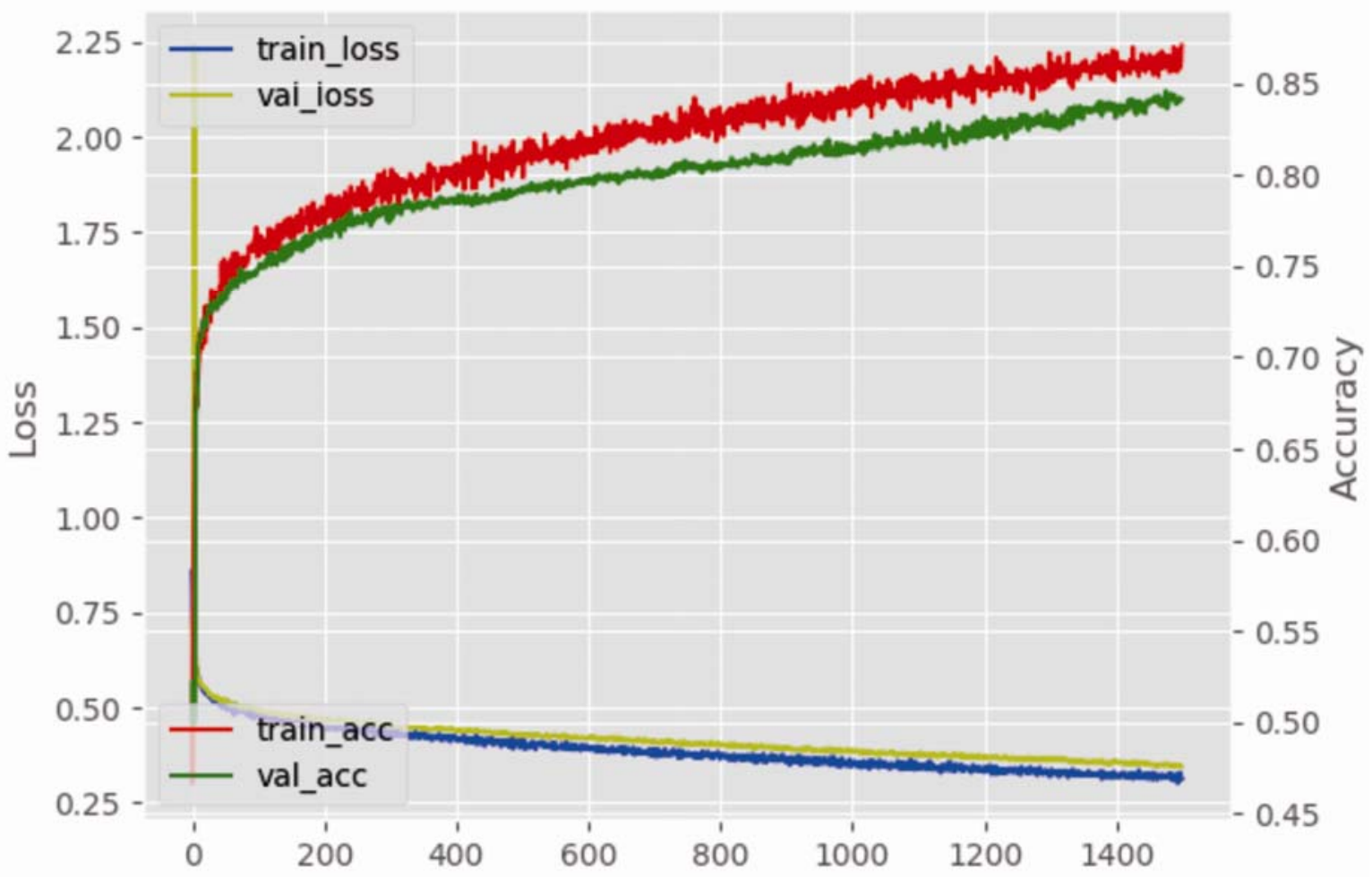

Figure 3. Training process on grayscale retinal photographs

Table 1 The performance of the model to screen for diabetes and hypertension on different dataset

\begin{tabular}{|l|l|l|}
\hline & Color retinal photographs & $\begin{array}{l}\text { Grayscale retinal } \\
\text { photographs }\end{array}$ \\
\hline Accuracy & $69.4 \%$ & $75.0 \%$ \\
\hline Precision & $65.3 \%$ & $70.0 \%$ \\
\hline Recall & $82.5 \%$ & $87.5 \%$ \\
\hline AUC & 0.745 & 0.803 \\
\hline AUPR & 0.742 & 0.779 \\
\hline
\end{tabular}


AUC: the area under the ROC; AUPR: the area under the Precision-Recall curve

There are many factors that affect the prediction accuracy of the model on separate test data samples, such as the hyper-parameters of the model including learning rate and momentum, the number of frozen layers, the number of patches randomly extracted from full image, and the size of and the proportion of patch to full image. Here are the optimal result, the others are not listed.

\section{Discussion}

Our study show that an already trained deep learning model based on the retinal fundus photographs alone can be used to screen for diabetes and hypertension. While not ideal, these results suggests that retinal images form the patients with diabetes or hypertension has distinguishing pathological features that are likely to generalize to other new images. Substantial prior research suggests that hypertension is associated with narrower retinal arterioles, ${ }^{2,3,5,9-11}$ decreased retinal vascular fractal dimension, ${ }^{3,17,19-21}$ less retinal arteriolar tortuosity $^{3,18}$ and diabetes has relation to wider retinal vessel, ${ }^{23-25,96}$ decreased retinal vascular fractal dimension, ${ }^{31}$ more retinal arteriolar tortuosity. ${ }^{30} \mathrm{~A}$ deep neural network model can detect these subclinical morphological vascular changes appearing below the threshold of a human observer.

Although we use strategies for mitigating overfitting and maximizing generalization, such as data augmentation and fine-tuning, on test data, the model eventually started over-fitting after a certain number of iterations. At the beginning of training, optimization and 
medRxiv preprint doi: https://doi.org/10.1101/2019.12.13.19013904; this version posted December 14, 2019. The copyright holder for this preprint (which was not certified by peer review) is the author/funder, who has granted medRxiv a license to display the preprint in perpetuity.

It is made available under a CC-BY-NC-ND 4.0 International license .

generalization were correlated: the higher the accuracy on training data, the higher the accuracy on test data. But at 53th epoch the model trained based on color retinal photographs begin to overfit and obtain increasingly worse results on test data which it has never seen before, while based on grayscale retinal photographs it begin to overfit at 193th epoch and the gap between validation accuracy and test accuracy was narrower. So the ideal model is one that was trained at 192 epochs using grayscale retinal photographs, and at this time it stands right at the border between underfitting and overfitting. One reason for this outcome is that we had little training data available. Another possible reason could be that the fundus photograph contains a lot of additional information besides retinal microvasculature and the model learns representations that are specific to the training data but that doesn't generalize to data outside of the training set. By converting the image to gray scale image, the additional information other than retinal vessel was compressed to the maximum extent and therefore the model trained using grayscale retinal photographs could achieve superior generalization power. To prevent a model from learning misleading or irrelevant patterns found in the training data, the best solution is to get more training data. Yet, the acquisition cost of medical image is higher and annotations must be performed by clinically qualified personals, and thousands of training images are usually beyond scope of biomedical research. Next, we construct an automated segmentation models for the retinal vessel segmentation task based on convolutional neural networks and only retained vessel morphology information. By implementing this methodology, a model can only learn retinal vascular pathological features from training dataset, thereby furthest mitigate overfitting.

Although the model's performance on screening for diabetes and hypertension is not so 
ideal, our study suggest that it has certain feasibility that screening people with cardiovascular risk factors based on retinal images using deep learning. Cardiovascular risk factors, which include hypertension, diabetes mellitus, dyslipidemia, obesity and so on, lead to characteristic changes of retinal vascular morphology in fundus photograph. In the future, we will assess large databases of subclinical cardiovascular patients who often have multiple cardiovascular risk factors and use deep learning technique to train screening models based on retinal photographs. So that people at high risk of cardiovascular disease may be discovered and treated at an early stage. 


\section{References}

1. Organization WH. WHO | The top 10 causes of death. Countries. 2013.

2. Hubbard LD, Brothers RJ, King WN et al. Methods for evaluation of retinal microvascular abnormalities associated with hypertension/sclerosis in the Atherosclerosis Risk in Communities Study. Ophthalmology. 1999;106:2269-2280.

3. Cheung CY, Tay WT, Mitchell P et al. Quantitative and qualitative retinal microvascular characteristics and blood pressure. J Hypertens. 2011;29:1380-1391.

4. Sharrett AR, Hubbard LD, Cooper LS et al. Retinal arteriolar diameters and elevated blood pressure: the Atherosclerosis Risk in Communities Study. Am J Epidemiol. 1999;150:263-270.

5. Wong TY, Hubbard LD, Klein R et al. Retinal microvascular abnormalities and blood pressure in older people: the Cardiovascular Health Study. Br J Ophthalmol. 2002;86:1007-1013.

6. Wang JJ, Mitchell P, Leung H, Rochtchina E, Wong TY, Klein R. Hypertensive retinal vessel wall signs in a general older population: the Blue Mountains Eye Study. Hypertension. 2003;42:534-541.

7. Yu T, Mitchell P, Berry G, Li W, Wang JJ. Retinopathy in older persons without diabetes and its relationship to hypertension. Arch Ophthalmol. 1998;116:83-89.

8. Klein R, Klein BE, Moss SE, Wang Q. Hypertension and retinopathy, arteriolar narrowing, and arteriovenous nicking in a population. Arch Ophthalmol. 1994;112:92-98.

9. Leung $\mathrm{H}$, Wang $\mathrm{JJ}$, Rochtchina $\mathrm{E}$ et al. Relationships between age, blood pressure, and retinal vessel diameters in an older population. Invest Ophthalmol Vis Sci. 2003;44:2900-2904.

10. Wong TY, Klein R, Klein BE, Meuer SM, Hubbard LD. Retinal vessel diameters and their associations with age and blood pressure. Invest Ophthalmol Vis Sci. 2003;44:4644-4650.

11. Sun C, Liew G, Wang JJ et al. Retinal vascular caliber, blood pressure, and cardiovascular risk factors in an Asian 
population: the Singapore Malay Eye Study. Invest Ophthalmol Vis Sci. 2008;49:1784-1790.

12. Mitchell $\mathrm{P}$, Cheung $\mathrm{N}$, de Haseth $\mathrm{K}$ et al. Blood pressure and retinal arteriolar narrowing in children. Hypertension. 2007;49:1156-1162.

13. Gopinath B, Wang JJ, Kifley A, Tan AG, Wong TY, Mitchell P. Influence of blood pressure and body mass index on retinal vascular caliber in preschool-aged children. J Hum Hypertens. 2013;27:523-528.

14. Li LJ, Cheung CY, Liu Y et al. Influence of blood pressure on retinal vascular caliber in young children. Ophthalmology. 2011;118:1459-1465.

15. Gopinath B, Baur LA, Wang JJ et al. Blood pressure is associated with retinal vessel signs in preadolescent children. J Hypertens. 2010;28:1406-1412.

16. Leung H, Wang JJ, Rochtchina E, Wong TY, Klein R, Mitchell P. Impact of current and past blood pressure on retinal arteriolar diameter in an older population. J Hypertens. 2004;22:1543-1549.

17. Liew G, Wang JJ, Cheung $\mathrm{N}$ et al. The retinal vasculature as a fractal: methodology, reliability, and relationship to blood pressure. Ophthalmology. 2008;115:1951-1956.

18. Cheung $\mathrm{CY}$, Zheng $\mathrm{Y}, \mathrm{Hsu}$ W et al. Retinal vascular tortuosity, blood pressure, and cardiovascular risk factors. Ophthalmology. 2011;118:812-818.

19. Cheung CY, Thomas GN, Tay W et al. Retinal vascular fractal dimension and its relationship with cardiovascular and ocular risk factors. Am J Ophthalmol. 2012;154:663-674.e1.

20. Sng CC, Wong WL, Cheung CY, Lee J, Tai ES, Wong TY. Retinal vascular fractal and blood pressure in a multiethnic population. J Hypertens. 2013;31:2036-2042.

21. Kurniawan ED, Cheung N, Cheung CY, Tay WT, Saw SM, Wong TY. Elevated blood pressure is associated with rarefaction of the retinal vasculature in children. Invest Ophthalmol Vis Sci. 2012;53:470-474.

22. Liew G, Sharrett AR, Wang JJ et al. Relative importance of systemic determinants of retinal arteriolar and venular 
caliber: the atherosclerosis risk in communities study. Arch Ophthalmol. 2008;126:1404-1410.

23. Tikellis $\mathrm{G}$, Wang $\mathrm{JJ}$, Tapp $\mathrm{R}$ et al. The relationship of retinal vascular calibre to diabetes and retinopathy: the Australian Diabetes, Obesity and Lifestyle (AusDiab) study. Diabetologia. 2007;50:2263-2271.

24. Islam FM, Nguyen TT, Wang JJ et al. Quantitative retinal vascular calibre changes in diabetes and retinopathy: the Singapore Malay eye study. Eye (Lond). 2009;23:1719-1724.

25. Nguyen TT, Wang JJ, Sharrett AR et al. Relationship of retinal vascular caliber with diabetes and retinopathy: the Multi-Ethnic Study of Atherosclerosis (MESA). Diabetes Care. 2008;31:544-549.

26. Liew G, Benitez-Aguirre P, Craig ME et al. Progressive Retinal Vasodilation in Patients With Type 1 Diabetes: A Longitudinal Study of Retinal Vascular Geometry. Invest Ophthalmol Vis Sci. 2017;58:2503-2509.

27. Li LJ, Lamoureux E, Wong TY, Lek N. Short-term poor glycemic control and retinal microvascular changes in pediatric Type 1 Diabetes patients in Singapore: a pilot study. BMC Ophthalmol. 2017;17:60.

28. Bucca BC, Maahs DM, Snell-Bergeon JK et al. Dynamic changes in retinal vessel diameter during acute hyperglycemia in type 1 diabetes. J Diabetes Complications. 2018;32:234-239.

29. Cheung CY, Lamoureux E, Ikram MK et al. Retinal vascular geometry in Asian persons with diabetes and retinopathy. J Diabetes Sci Technol. 2012;6:595-605.

30. Sasongko MB, Wong TY, Nguyen TT, Cheung CY, Shaw JE, Wang JJ. Retinal vascular tortuosity in persons with diabetes and diabetic retinopathy. Diabetologia. 2011;54:2409-2416.

31. Cheung N, Donaghue KC, Liew G et al. Quantitative assessment of early diabetic retinopathy using fractal analysis. Diabetes Care. 2009;32:106-110.

32. Sasongko MB, Wang JJ, Donaghue $\mathrm{KC}$ et al. Alterations in retinal microvascular geometry in young type 1 diabetes. Diabetes Care. 2010;33:1331-1336.

33. Wong TY, Islam FM, Klein $\mathrm{R}$ et al. Retinal vascular caliber, cardiovascular risk factors, and inflammation: the 
multi-ethnic study of atherosclerosis (MESA). Invest Ophthalmol Vis Sci. 2006;47:2341-2350.

34. Ikram MK, de Jong FJ, Vingerling JR et al. Are retinal arteriolar or venular diameters associated with markers for cardiovascular disorders? The Rotterdam Study. Invest Ophthalmol Vis Sci. 2004;45:2129-2134.

35. Leung H, Wang JJ, Rochtchina E, Wong TY, Klein R, Mitchell P. Dyslipidaemia and microvascular disease in the retina. Eye (Lond). 2005;19:861-868.

36. Myers CE, Klein R, Knudtson MD et al. Determinants of retinal venular diameter: the Beaver Dam Eye Study. Ophthalmology. 2012;119:2563-2571.

37. Dirani M, Xie J, Fenwick E et al. Are obesity and anthropometry risk factors for diabetic retinopathy? The diabetes management project. Invest Ophthalmol Vis Sci. 2011;52:4416-4421.

38. Rooney D, Lye WK, Tan G et al. Body mass index and retinopathy in Asian populations with diabetes mellitus. Acta Diabetol. 2015;52:73-80.

39. Man RE, Sabanayagam C, Chiang PP et al. Differential Association of Generalized and Abdominal Obesity With Diabetic Retinopathy in Asian Patients With Type 2 Diabetes. JAMA Ophthalmol. 2016;134:251-257.

40. Kurniawan ED, Cheung CY, Tay WT et al. The relationship between changes in body mass index and retinal vascular caliber in children. J Pediatr. 2014;165:1166-1171.e1.

41. Li LJ, Cheung CY, Chia A et al. The relationship of body fatness indices and retinal vascular caliber in children. Int $\mathrm{J}$ Pediatr Obes. 2011;6:267-274.

42. Gopinath B, Baur LA, Teber E, Liew G, Wong TY, Mitchell P. Effect of obesity on retinal vascular structure in pre-adolescent children. Int J Pediatr Obes. 2011;6:e353-359.

43. Taylor B, Rochtchina E, Wang JJ et al. Body mass index and its effects on retinal vessel diameter in 6-year-old children. Int J Obes (Lond). 2007;31:1527-1533.

44. Cheung N, Saw SM, Islam FM et al. BMI and retinal vascular caliber in children. Obesity (Silver Spring). 
2007;15:209-215.

45. Wang JJ, Taylor B, Wong TY et al. Retinal vessel diameters and obesity: a population-based study in older persons. Obesity (Silver Spring). 2006;14:206-214.

46. Gishti O, Jaddoe VW, Hofman A, Wong TY, Ikram MK, Gaillard R. Body fat distribution, metabolic and inflammatory markers and retinal microvasculature in school-age children. The Generation R Study. Int J Obes (Lond). 2015;39:1482-1487.

47. Kifley A, Liew G, Wang JJ et al. Long-term effects of smoking on retinal microvascular caliber. Am J Epidemiol. 2007;166:1288-1297.

48. Liew G, Baker ML, Wong TY et al. Differing associations of white matter lesions and lacunar infarction with retinal microvascular signs. Int J Stroke. 2014;9:921-925.

49. Kwa VI, van der Sande JJ, Stam J, Tijmes N, Vrooland JL, Amsterdam Vascular Medicine Group. Retinal arterial changes correlate with cerebral small-vessel disease. Neurology. 2002;59:1536-1540.

50. Qiu C, Cotch MF, Sigurdsson S et al. Retinal and cerebral microvascular signs and diabetes: the age, gene/environment susceptibility-Reykjavik study. Diabetes. 2008;57:1645-1650.

51. Hilal S, Ong YT, Cheung CY et al. Microvascular network alterations in retina of subjects with cerebral small vessel disease. Neurosci Lett. 2014;577:95-100.

52. Cheung N, Liew G, Lindley RI et al. Retinal fractals and acute lacunar stroke. Ann Neurol. 2010;68:107-111.

53. Lindley RI, Wang JJ, Wong MC et al. Retinal microvasculature in acute lacunar stroke: a cross-sectional study. Lancet Neurol. 2009;8:628-634.

54. De Silva DA, Wong TY, Chang HM et al. Is routine retinal examination useful in patients with acute ischemic stroke. Stroke. 2008;39:1352-1354.

55. Baker ML, Hand PJ, Wang JJ, Wong TY. Retinal signs and stroke: revisiting the link between the eye and brain. 
Stroke. 2008;39:1371-1379.

56. McGeechan K, Liew G, Macaskill $P$ et al. Prediction of incident stroke events based on retinal vessel caliber: a systematic review and individual-participant meta-analysis. Am J Epidemiol. 2009;170:1323-1332.

57. Wong TY, Klein R, Couper DJ et al. Retinal microvascular abnormalities and incident stroke: the Atherosclerosis Risk in Communities Study. Lancet. 2001;358:1134-1140.

58. Mitchell P, Wang JJ, Wong TY, Smith W, Klein R, Leeder SR. Retinal microvascular signs and risk of stroke and stroke mortality. Neurology. 2005;65:1005-1009.

59. Cooper LS, Wong TY, Klein R et al. Retinal microvascular abnormalities and MRI-defined subclinical cerebral infarction: the Atherosclerosis Risk in Communities Study. Stroke. 2006;37:82-86.

60. Cheung N, Rogers S, Couper DJ, Klein R, Sharrett AR, Wong TY. Is diabetic retinopathy an independent risk factor for ischemic stroke. Stroke. 2007;38:398-401.

61. Kawasaki R, Xie J, Cheung $\mathrm{N}$ et al. Retinal microvascular signs and risk of stroke: the Multi-Ethnic Study of Atherosclerosis (MESA). Stroke. 2012;43:3245-3251.

62. Cheung CY, Tay WT, Ikram MK et al. Retinal microvascular changes and risk of stroke: the Singapore Malay Eye Study. Stroke. 2013;44:2402-2408.

63. Ong YT, Wong TY, Klein R et al. Hypertensive retinopathy and risk of stroke. Hypertension. 2013;62:706-711.

64. Longstreth $\mathrm{W} \mathrm{Jr}$, Larsen EK, Klein $\mathrm{R}$ et al. Associations between findings on cranial magnetic resonance imaging and retinal photography in the elderly: the Cardiovascular Health Study. Am J Epidemiol. 2007;165:78-84.

65. Wong TY, Kamineni A, Klein R et al. Quantitative retinal venular caliber and risk of cardiovascular disease in older persons: the cardiovascular health study. Arch Intern Med. 2006;166:2388-2394.

66. Wang JJ, Liew G, Klein R et al. Retinal vessel diameter and cardiovascular mortality: pooled data analysis from two older populations. Eur Heart J. 2007;28:1984-1992. 
67. Ong YT, De Silva DA, Cheung CY et al. Microvascular structure and network in the retina of patients with ischemic stroke. Stroke. 2013;44:2121-2127.

68. Tedeschi-Reiner E, Strozzi M, Skoric B, Reiner Z. Relation of atherosclerotic changes in retinal arteries to the extent of coronary artery disease. Am J Cardiol. 2005;96:1107-1109.

69. Norgaz T, Hobikoglu G, Aksu H et al. Retinopathy is related to the angiographically detected severity and extent of coronary artery disease in patients with type 2 diabetes mellitus. Int Heart J. 2005;46:639-646.

70. Duncan BB, Wong TY, Tyroler HA, Davis CE, Fuchs FD. Hypertensive retinopathy and incident coronary heart disease in high risk men. Br J Ophthalmol. 2002;86:1002-1006.

71. Cheung N, Wang JJ, Klein R, Couper DJ, Sharrett AR, Wong TY. Diabetic retinopathy and the risk of coronary heart disease: the Atherosclerosis Risk in Communities Study. Diabetes Care. 2007;30:1742-1746.

72. Liew G, Wong TY, Mitchell P, Cheung N, Wang JJ. Retinopathy predicts coronary heart disease mortality. Heart. 2009;95:391-394.

73. Wong TY, Klein R, Sharrett AR et al. Retinal arteriolar narrowing and risk of coronary heart disease in men and women. The Atherosclerosis Risk in Communities Study. JAMA. 2002;287:1153-1159.

74. Wang JJ, Liew G, Wong TY et al. Retinal vascular calibre and the risk of coronary heart disease-related death. Heart. 2006;92:1583-1587.

75. McGeechan K, Liew G, Macaskill P et al. Risk prediction of coronary heart disease based on retinal vascular caliber (from the Atherosclerosis Risk In Communities [ARIC] Study). Am J Cardiol. 2008;102:58-63.

76. Liew G, Mitchell P, Rochtchina E et al. Fractal analysis of retinal microvasculature and coronary heart disease mortality. Eur Heart J. 2011;32:422-429.

77. Al-Fiadh AH, Wong TY, Kawasaki R et al. Usefulness of retinal microvascular endothelial dysfunction as a predictor of coronary artery disease. Am J Cardiol. 2015;115:609-613. 
78. Wang SB, Mitchell P, Liew G et al. A spectrum of retinal vasculature measures and coronary artery disease. Atherosclerosis. 2018;268:215-224.

79. Wong TY, Rosamond W, Chang PP et al. Retinopathy and risk of congestive heart failure. JAMA. 2005;293:63-69.

80. Cheung N, Bluemke DA, Klein R et al. Retinal arteriolar narrowing and left ventricular remodeling: the multi-ethnic study of atherosclerosis. J Am Coll Cardiol. 2007;50:48-55.

81. Cheung N, Wang JJ, Rogers SL et al. Diabetic retinopathy and risk of heart failure. J Am Coll Cardiol. 2008;51:1573-1578.

82. Wong TY, Shankar A, Klein R, Klein BE, Hubbard LD. Prospective cohort study of retinal vessel diameters and risk of hypertension. BMJ. 2004;329:79.

83. Wong TY, Klein R, Sharrett AR et al. Retinal arteriolar diameter and risk for hypertension. Ann Intern Med. 2004;140:248-255.

84. Smith W, Wang JJ, Wong TY et al. Retinal arteriolar narrowing is associated with 5-year incident severe hypertension: the Blue Mountains Eye Study. Hypertension. 2004;44:442-447.

85. Wang JJ, Rochtchina E, Liew G et al. The long-term relation among retinal arteriolar narrowing, blood pressure, and incident severe hypertension. Am J Epidemiol. 2008;168:80-88.

86. Tanabe Y, Kawasaki R, Wang JJ et al. Retinal arteriolar narrowing predicts 5-year risk of hypertension in Japanese people: the Funagata study. Microcirculation. 2010;17:94-102.

87. Ikram MK, Witteman JC, Vingerling JR, Breteler MM, Hofman A, de Jong PT. Retinal vessel diameters and risk of hypertension: the Rotterdam Study. Hypertension. 2006;47:189-194.

88. Kawasaki R, Cheung N, Wang JJ et al. Retinal vessel diameters and risk of hypertension: the Multiethnic Study of Atherosclerosis. J Hypertens. 2009;27:2386-2393.

89. Wong TY, Mohamed Q, Klein R, Couper DJ. Do retinopathy signs in non-diabetic individuals predict the subsequent 
medRxiv preprint doi: https://doi.org/10.1101/2019.12.13.19013904; this version posted December 14, 2019. The copyright holder for this preprint (which was not certified by peer review) is the author/funder, who has granted medRxiv a license to display the preprint in perpetuity. It is made available under a CC-BY-NC-ND 4.0 International license .

risk of diabetes. Br J Ophthalmol. 2006;90:301-303.

90. Tapp RJ, Tikellis G, Wong TY et al. Longitudinal association of glucose metabolism with retinopathy: results from the Australian Diabetes Obesity and Lifestyle (AusDiab) study. Diabetes Care. 2008;31:1349-1354.

91. Wong TY, Klein R, Sharrett AR et al. Retinal arteriolar narrowing and risk of diabetes mellitus in middle-aged persons. JAMA. 2002;287:2528-2533.

92. Wong TY, Shankar A, Klein R, Klein BE, Hubbard LD. Retinal arteriolar narrowing, hypertension, and subsequent risk of diabetes mellitus. Arch Intern Med. 2005;165:1060-1065.

93. Kifley A, Wang JJ, Cugati S, Wong TY, Mitchell P. Retinal vascular caliber and the long-term risk of diabetes and impaired fasting glucose: the Blue Mountains Eye Study. Microcirculation. 2008;15:373-377.

94. LeCun Y, Bengio Y, Hinton G. Deep learning. Nature. 2015;521:436-444.

95. He K, Zhang X, Ren S, Sun J. Deep Residual Learning for Image Recognition. In CVPR. 2015.

96. Kifley A, Wang JJ, Cugati S, Wong TY, Mitchell P. Retinal vascular caliber, diabetes, and retinopathy. Am J Ophthalmol. 2007;143:1024-1026. 
medRxiv preprint doi: https://doi.org/10.1101/2019.12.13.19013904; this version posted December 14, 2019. The copyright holder for this preprint (which was not certified by peer review) is the author/funder, who has granted medRxiv a license to display the preprint in perpetuity.

It is made available under a CC-BY-NC-ND 4.0 International license . 